\title{
ENSAYO
}

\section{Actualización de consentimiento informado de las clínicas odontológicas de la Facultad de Odontología de la Universidad Evangélica de El Salvador.}

\author{
Carmen Elisa Castro de Díaz \\ Sandra Elizabeth Grijalva ${ }^{2}$ \\ Recibido: 28/08/14 \\ Aceptado: 14/10/14
}

\section{Resumen}

En la Facultad de Odontología de la Universidad Evangélica de El Salvador (UEES), cada estudiante realiza tratamientos dentales durante los últimos 5 ciclos académicos, los cuales se hacen en pacientes que solicitan el servicio de las clínicas.

Cumpliendo con las normas nacionales e internacionales y tomando en cuenta los aspectos importantes en la redacción de un consentimiento informado, se elaboran tres documentos que se utilizarán en la clínica odontológica de la UEES. Se pretende que sirvan de modelo para las personas que deseen realizar un consentimiento para las investigaciones.

Se hizo una revisión de la documentación y normativa nacional e internacional y se elaboró una propuesta la cual puede servir de base para futuros modelos de consentimientos informados en las investigaciones de la facultad e institucionales que sus investigaciones lo necesiten.

1 Doctora en Cirugía Dental, Máster en Docencia Universitaria, Diplomada de Bioética de UNESCO y Presidenta del Comité de Ética para la Investigación de la Universidad Evangélica de El Salvador (CEI-UEES) e-mail: Carmen.castro@uees.edu.sv. 


\section{Introducción}

En algunas instituciones relacionadas con atención en salud, no se da la debida importancia ni el valor que tienen los datos obtenidos en las fichas de los pacientes; en nuestro país no se cuenta con un sistema que recoja esta información y sea utilizada con fines epidemiológicos, hasta hace pocos años se han observado esfuerzos por algunas entidades e instituciones que se ocupan de ello. En este ensayo se da a conocer la normativa internacional como base para elaborar un consentimiento informado, los elementos que lo conforman y la importancia de elaborar para todo procedimiento clínico que se retome con fines de investigación.

\section{Metodología de la Investigación}

Se deben revisar documentos internacionales para la elaboración del consentimiento, como la Declaración de Helsinki, ${ }^{1}$ que afirma que la investigación científica está sujeta a normas éticas las cuales son base para promover el respeto a todos los seres humanos.

El documento se debe redactar con elementos y vocabulario claro, e incluir la persona responsable a la que los pacientes podrán dirigirse si no están de acuerdo con algún procedimiento, tratamiento o resultado, como lo dicta la normativa de investigación científica internacional, estos datos no solo son el nombre, sino también la información de contacto del investigador responsable.

La Declaración Universal sobre Bioética y Derechos Humanos, ${ }^{2,7}$ inicialmente afirma el hecho de "respetar plenamente la dignidad humana, los derechos humanos y las libertades fundamentales, así como los intereses y el bienestar de la persona que deberá tener prioridad con respecto al interés exclusivo de la ciencia o la sociedad."
La práctica que se realice en el proceso de investigación deberá potenciar al máximo los beneficios directos e indirectos para los sujetos de investigación, es decir reducir al máximo los posibles efectos nocivos.

En el caso de El Salvador a partir de Abril de 2009 se oficializó la Ley de protección integral a la niñez y adolescencia, ${ }^{3}$ (LEPINA) en el artículo 19 especialmente se refiere a la prohibición de experimentación y prácticas que atenten contra la vida en la que se lee textualmente: "Se prohíbe cualquier tipo de actividad que atente contra la vida, dignidad o integridad física, psíquica o moral de las niñas, niños y adolescentes, tales como:

a) Experimentación médica.

b) Experimentación genética.

c) Prácticas étnicas, culturales o sociales".

El artículo 6 de la Declaración habla sobre el consentimiento, en donde se lee que:

"Toda intervención médica preventiva, diagnóstica y terapéutica sólo habrá de llevarse a cabo previo consentimiento libre e informado de la persona interesada, basado en la información adecuada. Cuando proceda, el consentimiento deberá ser claro y la persona interesada podrá revocarlo en todo momento y por cualquier motivo, sin que esto implique desventaja o perjuicio alguno". Atendiendo a lo anterior el consentimiento será redactado de forma clara, para que sea fácilmente comprendido, si el sujeto de investigación no puede leer o interpretar alguna palabra o frase, los responsables de la investigación deberán explicar y solventar las dudas.

El Artículo 8 habla sobre el respeto de la vulnerabilidad humana y la integridad personal. Es decir, que los individuos y grupos especialmente vulnerables deberían 
ser protegidos y se debería respetar la integridad personal de dichos individuos, un ejemplo de ello son las personas con discapacidades físicas o mentales y las personas privadas de libertad o personas ingresadas en asilos, y que fungen como sujetos de investigación, por ejemplo.

La privacidad de las personas interesadas y la confidencialidad de la información que les atañe deberían respetarse, esto es ampliamente abordado en el Artículo 9 que sugiere que "En la mayor medida posible, esa información no debería utilizarse o revelarse para fines distintos de los que determinaron su fase de recolección o para los que se obtuvo el consentimiento, de conformidad con el derecho internacional, en particular el relativo a los derechos humanos".

En el Artículo 10, se manifiesta la importancia de respetar la Igualdad, justicia y equidad. Con respecto a eso en el consentimiento informado debe quedar plasmado como se habrá de respetar la igualdad fundamental de todos los participantes y como se respetaran sus derechos, de tal modo que sean tratados con justicia y equidad.

El Artículo 11, habla sobre la no discriminación y no estigmatización. Esto se refiere a que ningún individuo o grupo debería ser sometido por ningún motivo, en violación de la dignidad humana, los derechos humanos y las libertades fundamentales, a discriminación $\mathrm{o}$ estigmatización alguna. No se publicarán nombres 0 datos que comprometan la identidad y dignidad de las personas, las fotografías que sean utilizadas para fines didácticos o de estudio, serán protegidas de tal manera de cuidar la identidad de la persona. Los pacientes podrán acudir a los investigadores si en algún momento desean conocer la finalidad o el uso que se le da a la información que se obtiene de ellos.

\section{ELementos del consentimiento informado}

Según la Organización Panamericana de la Salud (OPS), en su Documento de las Américas de Buenas Prácticas Clínicas, ${ }^{4}$ menciona que es muy importante crear o seleccionar la información que se incluirá en el proceso de consentimiento informado, el cual debe incluir las siguientes pautas:

Descripción de la investigación y la función del participante, incluye una explicación de todos los procedimientos pertinentes al participante.

Descripción de los riesgos razonablemente previsibles.

\section{Descripción de los beneficios esperados}

Alternativas de participación, como otros estudios o servicios.

Explicación de la confidencialidad.

Explicación de las normas de indemnización por lesiones o problemas de salud como consecuencia de haber participado en el estudio.

Datos sobre quién contactar respecto a la investigación si el participante tiene preguntas o inquietudes.

Explicación que la participación es voluntaria.

Es importante tomar en cuenta que no se debe pensar en la cantidad de información que se coloca en cada hoja sino más bien en la calidad de información que posee y las palabras que se utilicen deberán ser lo más claras para la persona que lo firmará. ${ }^{8}$

El consentimiento puede ser individual o colectivo, es decir que se puede leer la información general a un grupo de personas y luego firmar. Esto se hace cuando la información será recopilada en una sola sesión y se hace de forma colectiva a un grupo grande de personas. 


\section{Conclusiones}

El sujeto de investigación debe de estar totalmente claro del uso que se le da a la información que proporciona el sujeto de investigación.

Se debe dar a conocer los logros obtenidos en los estudios con seres humanos al utilizar esta información como datos para investigaciones.

Se debe promover en la UEES que las investigaciones en que se redacte consentimiento informado pasen por el Comité de Ética para la Investigación, y realizar la evaluación.

\section{Recomendaciones}

Los investigadores deberán revisar modelos de consentimiento informado, para tomar ejemplo de ellos.

Es necesario revisar los principios bioéticos y las partes elementales de un consentimiento informado, dictadas por las normativas internacionales.

Debe revisar la legislación de cada país y región.

Los investigadores pueden solicitar al Comité de Ética para la Investigación de la UEES, los formatos para someter su investigación a evaluación.

\section{Fuentes Consultadas}

1. Declaración de Helsinki de la Asociación Médica Mundial Principios éticos para las investigaciones médicas en seres humanos $59^{a}$ Asamblea General, Seúl, Corea, octubre 2008.Principios para toda la investigación médica. Página 2 a 5. Disponible en Internet: www.buenosaires.gob.ar/areas/salud/ dircap/investigacion/declaraciones_helsinski.pdf

2. Organización de las Naciones Unidas para la Educación, la Ciencia y la Cultura UNESCO Declaración universal sobre Bioética y Derechos Humanos.19 de octubre de 2005. Principios $\# 3,5,6,8,9,10$ y 11 .Disponible en Internet: www. unav.es/cdb/unebioetica.pdf

3. Ley de protección integral a la niñez y adolescencialey LEPINA Comisión Coordinadora del Sector Justicia (UTE) 2009.Art. 19.Pagina No. 10.

4. Organización Panamericana de la Salud (OPS), Documento de las América de Buenas PrácticasClínicas. Capítulo 4: Consentimiento informadoPáginas \#14,15,16 y 17Disponible en Internet :http://www.ms.gba.gov.ar/sitios/ccis/ files/2012/08/DocumentoAmericas.pdf

5. Reglamento de dirección de clínicas de la Facultad de Odontología de la Universidad Evangélica de El Salvador

6. Guía operativa del comité deética para la investigación de la Universidad Evangélica de El Salvador

7. Tealdi, J.C. Diccionario latinoamericano de bioética. Bogotá UNESCO Red latinoamericana y del caribe de bioética Universidad Nacional de Colombia, 2008. disponible en: http://unesdoc. unesco.org/images/0016/001618/161848s.pdf consultado en $06 / 10 / 14$

8. Keith McAdam, LA ÉTICA DE LA INVESTIGACIÓN RELACIONADA CON LA ATENCIÓN DE SALUD EN LOS PAÍSES EN DESARROLLO Nuffield Council on Bioethics Abril de 2002. disponible en http:// actabioethica.cl/docs/acta9.pdf. consultado 06/10/14 